\title{
Systemic and cerebral vascular endothelial growth factor levels increase in murine cerebral malaria along with increased calpain and caspase activity and can be reduced by erythropoietin treatment
}

\author{
Casper Hempel ${ }^{1,2} *$, Nils Hoyer ${ }^{1,2}$, Anna Kildemoes ${ }^{1,2}$, Charlotte Bille Jendresen ${ }^{1,2}$ and Jørgen Anders \\ Lindholm Kurtzhals ${ }^{1,2}$
}

${ }^{1}$ Centre for Medical Parasitology, Department of Clinical Microbiology, Copenhagen University Hospital, Copenhagen, Denmark

${ }^{2}$ Department of International Health, Immunology and Microbiology, University of Copenhagen, Copenhagen, Denmark

\section{Edited by:}

Pietro Ghezzi, Brighton and Sussex Medical School, UK

Reviewed by:

Stephane Picot, University Lyon 1 , France

Delmiro Fernandez-Reyes, Brighton and Sussex Medical School, UK

*Correspondence:

Casper Hempel, Department of Clinical Microbiology, Copenhagen University Hospital, Ole Maaløesvej 26, Copenhagen N 2200, Denmark e-mail: casperhempel@gmail.com
The pathogenesis of cerebral malaria $(\mathrm{CM})$ includes compromised microvascular perfusion, increased inflammation, cytoadhesion, and endothelial activation. These events cause blood-brain barrier disruption and neuropathology and associations with the vascular endothelial growth factor (VEGF) signaling pathway have been shown. We studied this pathway in mice infected with Plasmodium berghei ANKA causing murine CM with or without the use of erythropoietin (EPO) as adjunct therapy. ELISA and western blotting was used for quantification of VEGF and relevant proteins in brain and plasma. CM increased levels of VEGF in brain and plasma and decreased plasma levels of soluble VEGF receptor 2. EPO treatment normalized VEGF receptor 2 levels and reduced brain VEGF levels. Hypoxiainducible factor (HIF)- $1 \alpha$ was significantly upregulated whereas cerebral HIF-2 $\alpha$ and EPO levels remained unchanged. Furthermore, we noticed increased caspase- 3 and calpain activity in terminally ill mice, as measured by protease-specific cleavage of $\alpha$-spectrin and p35. In conclusion, we detected increased cerebral and systemic VEGF as well as HIF-1 $\alpha$, which in the brain were reduced to normal in EPO-treated mice. Also caspase and calpain activity was reduced markedly in EPO-treated mice.

Keywords: cerebral malaria, erythropoietin, neuropathology, VEGF, hypoxia, brain, inflammation

\section{INTRODUCTION}

Cerebral malaria $(\mathrm{CM})$ is one of the most severe complications of malaria causing substantial morbidity and mortality mainly in Sub-Saharan Africa (1). At present, the pathogenesis remains incompletely understood but includes cytoadhering, infected erythrocytes, leukocytes, and platelets as well as dysregulated inflammation and coagulation cascades (2). Due to the apparent cerebral hypoxia in human and murine CM (3-6), adjunctive strategies, which aim to overcome this, could potentially improve outcome.

The physiological response to hypoxia is stabilization of hypoxia-inducible factor (HIF)- $1 \alpha$ and HIF- $2 \alpha$, which will dimerize with the $\beta$ subunit and via binding to hypoxia responsive elements adapt the cell to low oxygen levels (7). HIF-1 $\alpha$ and HIF$2 \alpha$ upregulate the transcription of a multitude of cytokines and growth factors $(8,9)$, but the two transcription factors induce expression of different proteins (10). One of the HIF-regulated proteins is the pleiotropic cytokine erythropoietin (EPO) mainly regulated by HIF- $2 \alpha$ (11). EPO has been associated with protection of cells and tissue beyond the hematopoietic lineage $(12,13)$. Furthermore, it improves survival in murine $\operatorname{CM}(5,14-16)$ and is a safe adjunctive treatment in Malian children (17). Also, the cerebral hypoxia detectable in terminally ill CM mice was reversed by exogenous EPO treatment (5).

Besides EPO, the expression of vascular endothelial growth factor-A (VEGF) is HIF-dependently upregulated in response to hypoxia (18), mainly by HIF-1 $\alpha$ (19). VEGF is a survival factor for the endothelium but also stimulates opening of the blood-brain barrier (BBB) to facilitate angiogenesis and tissue oxygenation (20). This event is essential in developmental angiogenesis when organs are vascularized. Thus, hypoxia may stimulate unwanted BBB disruption during CM and pathological angiogenesis (21). Increased levels of VEGF and its cleaved receptors (VEGFR1/Flt1 and VEGFR2/Flk-1) have been found in plasma and brains from CM patients (22-27) suggesting an association with cerebral pathology. On the other hand, high levels of EPO have been associated with a lower risk of neurological sequelae in children suggesting a neuroprotective effect (23).

Plasmodium berghei ANKA was recently shown to induce high VEGF levels in plasma promoting acute lung injury in mice (28). Despite noticeable cerebral hypoxia in murine CM using $P$. berghei ANKA (5), it is not known how hypoxia affects angiogenic signaling in murine CM. Here we assess the hypoxia-associated transcription factors and proteins in the brain in terminally ill $\mathrm{CM}$ mice as well as the plasma levels of angiogenesis-associated proteins.

\section{MATERIALS AND METHODS}

MICE, PARASITES, AND INFECTION

Forty, 7 weeks old, female C57BL/6 mice (Taconic, Ejby, Denmark) were used for the experiment. The mice were randomly assigned 
to one of four experimental groups: uninfected and saline-treated (UninfSal), uninfected and EPO-treated (5000 IU/kg, day 4-7 post infection (p.i.)) (UninfEPO), infected with $10^{4}$ P. berghei ANKA and saline-treated day 4-7 p.i. (InfSal) or infected with $10^{4} P$. berghei ANKA and EPO-treated day 4-7 p.i. (InfEPO). Injections of parasites and treatments were performed intraperitoneally (i.p.) and the volume was in all cases $200 \mu \mathrm{l}$. Cryo-preserved parasites were passed once in $\mathrm{C} 57 \mathrm{BL} / 6$ mice counting viable parasites only for the experimental infection, as previously described (14). Uninfected mice received isotonic saline, which was used as diluent for the parasite inocula. EPO was also diluted in saline and thus vehicle-treated mice received saline only. Parasitemia was determined using flow cytometry by staining circulating cells with acridine orange as previously described (29). Body temperature was measured with a rectal probe (Ellab, Denmark) during the infection. A drop below $32^{\circ} \mathrm{C}$ was used as a proxy for death as previously described $(30,31)$. Animal experiments were approved by the Danish Animal Inspectorate (license number 2006/561-1128).

\section{TERMINATING THE ANIMAL EXPERIMENT AND TISSUE PROCESSING}

At day 8, InfSal mice showed clinical signs of CM including decreased body temperature, impaired movement, convulsions, and loss of coordination and all mice were killed. Behavioral changes were assessed qualitatively by placing mice on a $1 \mathrm{~cm}$ thin bar and by placing the mice on the cage lid and gradually increasing steepness. In deep anesthesia (mixture of $63 \mu \mathrm{g}$ fentanyl, $2 \mathrm{mg}$ fluanisone, and $1 \mathrm{mg}$ midazolam pr. mouse), blood was collected in heparin from the orbital sinus and plasma was separated by centrifugation and stored at $-20^{\circ} \mathrm{C}$ until use. The mice were transcardially perfused with heparinized (15000 IU/l, Leo Pharma, Denmark) isotonic saline and brain tissue was removed, snap-frozen in liquid nitrogen, and stored at $-20^{\circ} \mathrm{C}$ until used.

\section{WESTERN BLOTS}

Frozen brains were thawed on ice and homogenized in ice cold lysis buffer [50 mM Tris- $\mathrm{HCl}, 5 \mathrm{mM}$ EDTA, 1\% Triton X-100, $1 \mathrm{mM}$ dithiothreitol (DTT) ] with added protease inhibitors (Complete Mini, Roche, Denmark) using a Heidolph disperser (SilentCrusher M, Heidolph Instruments, Germany). Protein content of the lysates was determined using the Lowry assay (DC protein assay, Bio-Rad, CA, USA). The proteins were reduced in
Laemmli buffer with $200 \mu$ M DTT (Sigma-Aldrich, Copenhagen, Denmark) and boiled for 5 min before separation on $10 \%$ polyacrylamide gels (BisTris, Life Technologies, Carlsbad, CA, USA) at 150 V (constant V, EPS2A200, Amersham Biosciences, Ge Healthcare, Brondby, Denmark) for 60-70 min using MES or MOPS buffer (Life Technologies) depending on protein size (Table 1). Thirty micrograms protein was loaded into each well. Proteins were transferred to polyvinylidene membranes (Immun-Blot, BioRad) at $30 \mathrm{~V}$ (constant V, Amersham Biosciences) for $60 \mathrm{~min}$. Membranes were blocked with 5\% skimmed milk powder (Fluka, Sigma-Aldrich) or $5 \%$ bovine serum albumin (Sigma-Aldrich) in tris-buffered saline (TBS, Sigma-Aldrich) depending on the protein being detected (Table 1) for $60 \mathrm{~min}$ at room temperature. Proteins were detected with primary antibodies diluted in blocking solution (Table 1) over night at $4^{\circ} \mathrm{C}$. After washing in TBS supplemented with $0.05 \%$ Tween-20 (Sigma-Aldrich), horse radish peroxidase (HRP)-conjugated secondary antibodies (Dako, Glostrup, Denmark) diluted in blocking solution were applied for $60 \mathrm{~min}$ at room temperature. Antibody binding was visualized with chemiluminescent substrates: Super Signal or West Femto (Pierce, Thermo-Fischer Scientific, IL, USA) on a gel-doc imager (Bio-Rad XRS, Bio-Rad) depending on abundance. Expression levels were normalized to $\beta$-tubulin levels (Abcam, UK).

\section{ELISA}

Plasma was analyzed for VEGF, soluble Flt-1 (sFlt-1), and soluble Flk-1 (sFlk-1) according to manufacturer's instructions (Quantikine, R\&D Systems, UK). Angiopoietin-1 levels were measured in 25-50 $\mu$ l plasma according to manufacturer's instructions with the modification that blocking was achieved with 5\% BSA (Quantikine DuoSet, R\&D Systems). Brain homogenates (diluted to $2 \mathrm{mg}$ protein/ml) were analyzed for VEGF content according to manufacturer's instructions (Quantikine, R\&D Systems). Brain VEGF levels were adjusted to pg VEGF/mg total protein.

\section{STATISTICAL ANALYSES}

When data followed a normal distribution and had similar variances they were analyzed by one-way ANOVA followed by post hoc $t$-tests with Holm correction. When data did not display normal distribution and equal variance, Kruskal-Wallis test with pairwise Wilcox tests with Holm correction was applied. These data

Table 1 | Overview of antibodies used for western blots.

\begin{tabular}{|c|c|c|c|c|c|c|}
\hline Antibody & Company & $\begin{array}{l}\text { Catalogue } \\
\text { number }\end{array}$ & $\begin{array}{l}\text { Dilution for } \\
\text { WB }(x)\end{array}$ & Blocking agent & Running buffer & $\begin{array}{l}\text { Luminescent } \\
\text { substrate }\end{array}$ \\
\hline $\mathrm{HIF}-1 \alpha$ & Novus Biologicals & NB100-131A1 & 2000 & Skim milk & MOPS & Femtosignal \\
\hline HIF- $2 \alpha$ & Thermo Scientific & PA1-16510 & 500 & Skim milk & MOPS & Femtosignal \\
\hline Erythropoietin & Santa Cruz & Sc-7956 & 250 & Skim milk & MES & ECL Plus \\
\hline$\alpha$-Spectrin & Millipore & MAB1622 & 1000 & Skim milk & MOPS & Femtosignal \\
\hline P35/25 & Cell Signaling Technology & C64B10 & 1000 & BSA & MES & ECL Plus \\
\hline$\beta$-tubulin & Abcam & Ab6046 & 2000 & Depending on target & Depending on target & Depending on target \\
\hline
\end{tabular}

Antibodies were diluted in 5\% skimmed milk powder in TBS (FLUKA) for WB and in 5\% BSA in TBS (Sigma-Aldrich). Depending on size of the protein of interest, samples were separated with either a MES or MOPS based running buffer (Life Technologies). Depending on antigen abundance, the antibody recognition was assessed with either ECL plus or femtosignal enhancement (Pierce). 
are shown as median with interquartile ranges in box plots. All statistics was carried out using $\mathrm{R}$ for windows version 2.15.2 (32).

\section{RESULTS}

\section{CLINICAL PARAMETERS}

The infection progressed in a similar manner to what has been described before $(5,33)$. At day 8 p.i. the majority of the InfSal mice were terminally ill with clinical signs of murine CM. Ninety percentage had impaired movement and coordination. Thirty percentage had convulsions. InfEPO mice showed only minor clinical signs of CM (only $20 \%$ had ruffled fur). Statistical analyses revealed a significant change in body temperature on day 7 p.i. (Figure 1A, $p<0.001)$ and day 8 p.i. $(p<0.001)$, but not earlier $(p>0.10)$. At day 7 p.i., InfEPO mice had significantly higher body temperature than both groups of uninfected mice $(p<0.003)$ and InfSal mice had significantly higher body temperature than UninfSal mice $(p=0.008)$. At day 8 p.i., InfSal mice had significantly lower body temperature than any other group of mice $(p<0.005)$. Parasitemia rose gradually to similar levels in both infected groups until day 5 (Figure $1 B, p=0.8$ ). From day 7 p.i. and onward, InfSal mice had significantly increased parasitemia compared with InfEPO (day 7 p.i.: $p=0.002$; day 8 p.i.: $p<0.001)$.

\section{INCREASED CEREBRAL LEVELS OF VEGF, EPO AND THEIR TRANSCRIPTION FACTORS IN TERMINAL CM}

From western blotting, we detected a significant increase of HIF$1 \alpha$ in terminal CM (Figure $2 \mathrm{~A}, p=0.04$ ). Only InfSal mice were significantly different from UninfSal mice $(p=0.04)$.

Correspondingly, we detected a change in cerebral VEGF levels (Figure 2B, $p=0.008$ ). In terminally ill CM mice, cerebral VEGF content was increased significantly compared to UninfSal mice $(p=0.02)$. Other groups were statistically indistinguishable from UninfSal mice. In contrast to HIF- $1 \alpha$, the main transcriptional regulator of EPO, cerebral HIF-2 $\alpha$, was expressed at comparable levels in all four experimental groups (Figure 2C, $p=0.1$ ). Similarly, cerebral EPO levels were comparable in all groups (Figure 2D, $p=0.2)$.

\section{CALPAIN AND CASPASE-3 ACTIVITY IN TERMINAL CM}

We used non-erythroid $\alpha$-spectrin as a marker of protease activity, since it contains distinct cleavage sites for calpain- and caspase3 activity (34). $\alpha$-Spectrin is cleaved by calpain, resulting in additional bands at 150 and $145 \mathrm{kDa}$, and by caspase- 3 activity (apoptosis pathway) resulting in a band at $120 \mathrm{kDa}$. While total $\alpha$-spectrin levels remained unaltered (results not shown), one band associated with calpain activity was significantly upregulated in InfSal mice $(150 \mathrm{kDa}$, Figure $3 \mathrm{~A}, p=0.04)$ while the other was not $(145 \mathrm{kDa}$, Figure $3 \mathrm{~B}, p=0.07)$ compared with UninfSal mice. Also caspase- 3 activity was significantly increased (Figure $3 \mathrm{C}, p=0.001$ ) in InfSal mice as compared to the other groups $(p<0.01)$.

The activation of calpain activity was confirmed by assessing p35 levels, since calpain activity results in cleavage of p35 into a smaller protein at $25 \mathrm{kDa}$ (p25) (34). p35 levels were indistinguishable between groups ( $p=0.2$, data not shown), while p25 levels were significantly different (Figure 3D, $p=0.02$ ). InfSal mice had significantly higher p25 levels than other groups $(p<0.05)$ and p25 levels were not detectable above background in UninfEPO mice.

\section{INCREASED PLASMA LEVELS OF VEGF AND DECREASED SOLUBLE FLK-1 LEVELS IN TERMINAL CM}

Infection lead to a significant increase in plasma VEGF levels $(p=0.004$, Figure 4A). Both InfSal and InfEPO mice had significantly higher levels compared with uninfected controls $(p=0.04$ and $p=0.03$, respectively). sFlt- 1 was changed at day 8 p.i. $(p=0.02$, Figure $4 \mathrm{~B})$. However, only InfEPOtreated vs. InfSal were statistically distinguishable $(p=0.04)$. sFlk-1 levels were significantly decreased in terminal murine $\mathrm{CM}(p<0.001$, Figure $4 \mathrm{C})$. EPO treatment led to an increased level of this receptor in both infected $(p=0.03)$ and uninfected mice $(p=0.02)$ compared with saline-treated control groups. Yet, infection still decreased sFlk-1 levels in InfEPO mice $(p<0.001)$ compared with UninfEPO mice. The sFlt-1/sFlk1 ratio was higher in InfSal than any other group $(p<0.002$, Figure 4D).

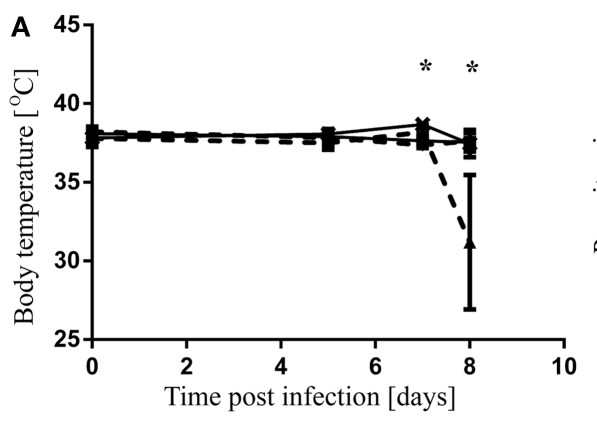

.. UninfSaline $\rightarrow$ UninfEPO

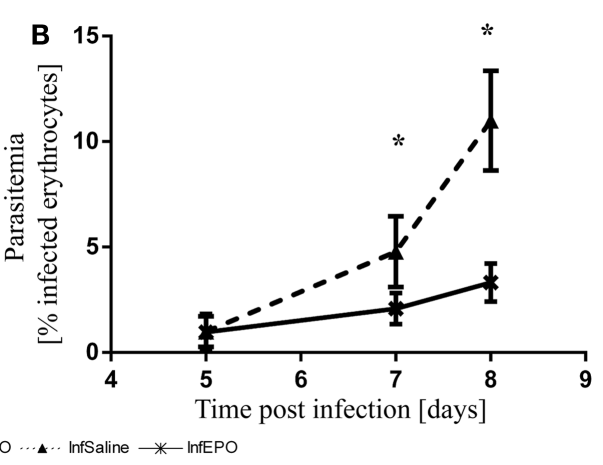

FIGURE 1 | Progression of body temperature and parasitemia during the course of infection. (A) Body temperature remained stable until day 6 p.i. and increased slightly in infected mice. InfSal mice displayed clinical signs of $\mathrm{CM}$ at day 8 p.i. and had significantly lowered body temperature $(p<0.005)$.
(B) Parasitemia rose gradually in both groups but did not increase as fast in InfEPO mice from day $7 p . i$ and onward $(p<0.05)$. Data are represented as mean values and error bars display standard deviation. Significant deviations from uninfected, saline-treated mice are denoted with an asterisk. 

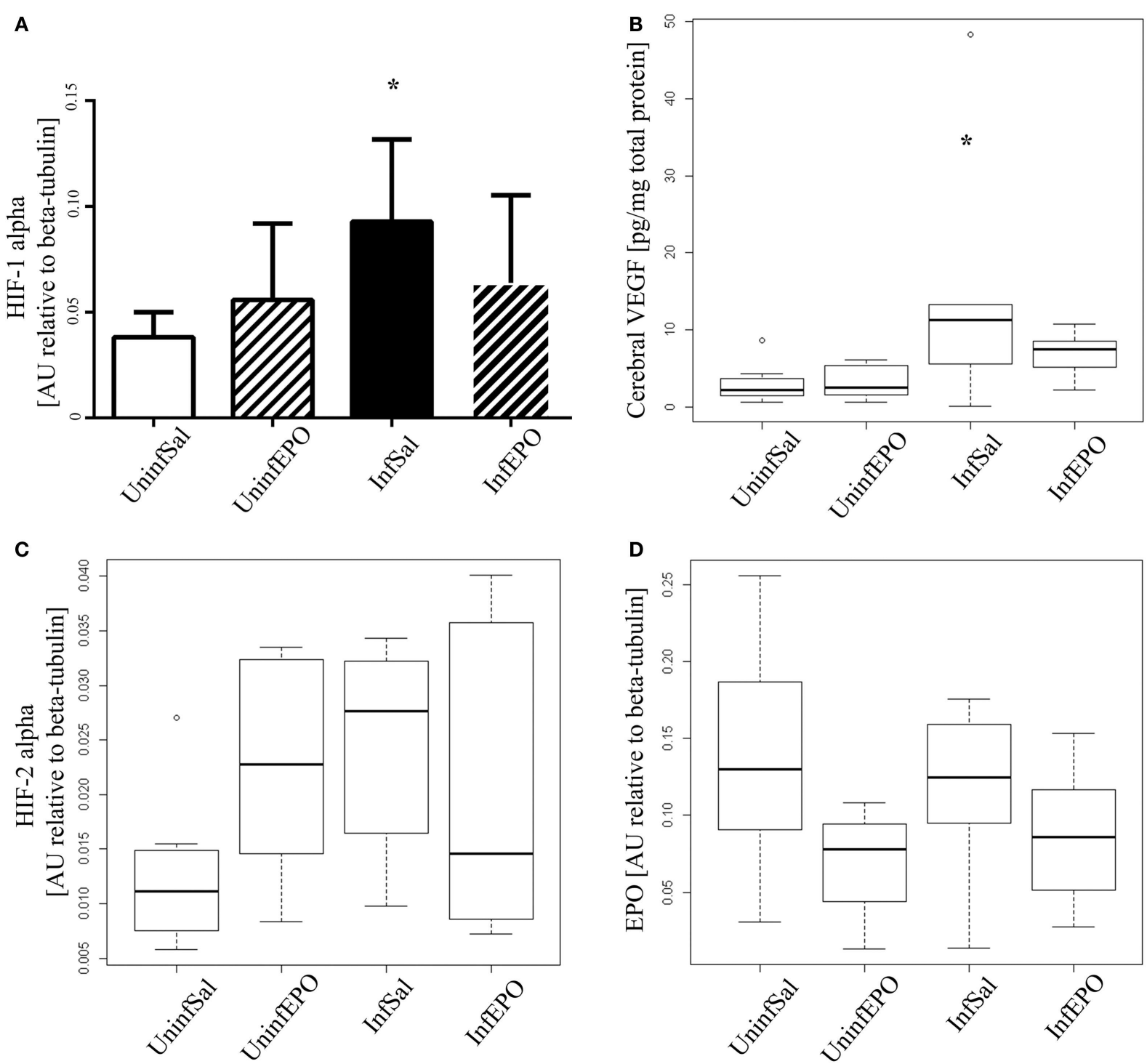

FIGURE 2 | Cerebral expression of HIF-1 $\alpha$, VEGF, HIF-2 $\alpha$, and EPO.

(A) HIF-1 $\alpha$ levels were significantly increased in InfSal mice compared with UninfSal $(p=0.04)$. The other groups were statistically indistinguishable. (B) VEGF was analyzed with ELISA, showing a significant increase in InfSal mice compared with uninfected mice $(p=0.02)$. InfEPO was increased though not statistically significantly.

\section{PLASMA ANGIOPOIETIN-1 LEVELS ARE DECREASED IN TERMINALLY ILL MICE}

High levels of angiopoietin-1 are associated with endothelial stability (35) and aberrant angiopoietin-1 and angiopoietin-2 levels have been proposed as good biomarkers for severe malaria (36). Statistical analyses showed different levels of angiopoietin1 in the experimental groups ( $p=0.001$, Figure 5) with marked reduction of angiopoietin-1 levels in terminally ill InfSal mice $(p=0.004)$. InfEPO mice also tended to have lower angiopoietin-1 levels although this was not significantly different from uninfected mice $(p=0.06)$.

(C) HIF-2 $\alpha$ expression was similar in all four groups. (D) Also, EPO was expressed in the same level in all four groups. Bar charts (A) show mean values and standard deviation. Box plots (B-D) show median values and interquartile ranges. Whiskers show Tukey hinges; open circles are outliers. Asterisks denote significant deviations from uninfected, saline-treated mice. 

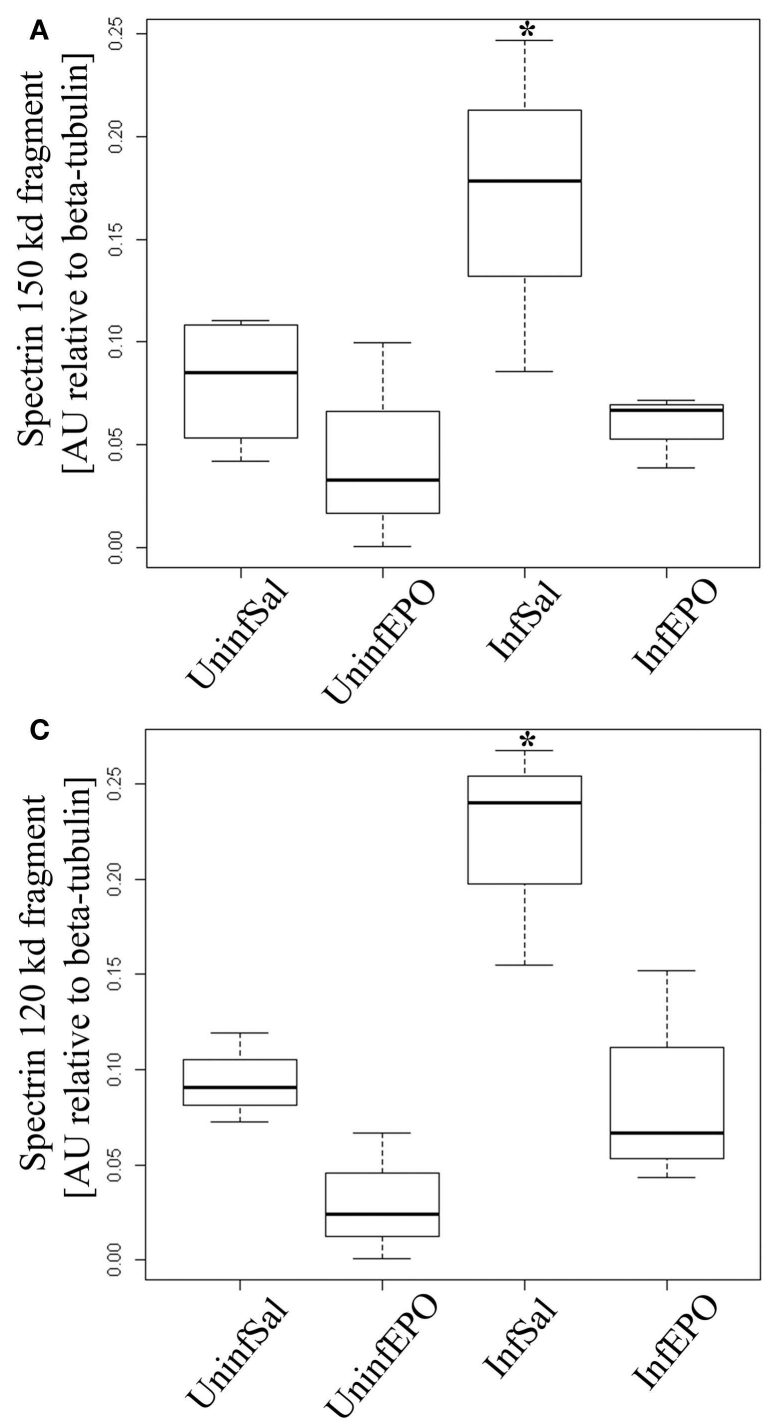

FIGURE 3 | Calpain and caspase activity in terminal CM. Activity of caspase-3 and calpain was assessed by looking for specific cleavage products. (A) Analyzing the $150 \mathrm{kDa}$ fragment of $\alpha$-spectrin specific for calpain activity show a significant increase in InfSal mice $(p=0.04)$ compared with uninfected mice. (B) No significant change was noted when analyzing the $145 \mathrm{kDa}$ fragment, also specific for calpain activity. (C) The $120 \mathrm{kDa}$ band
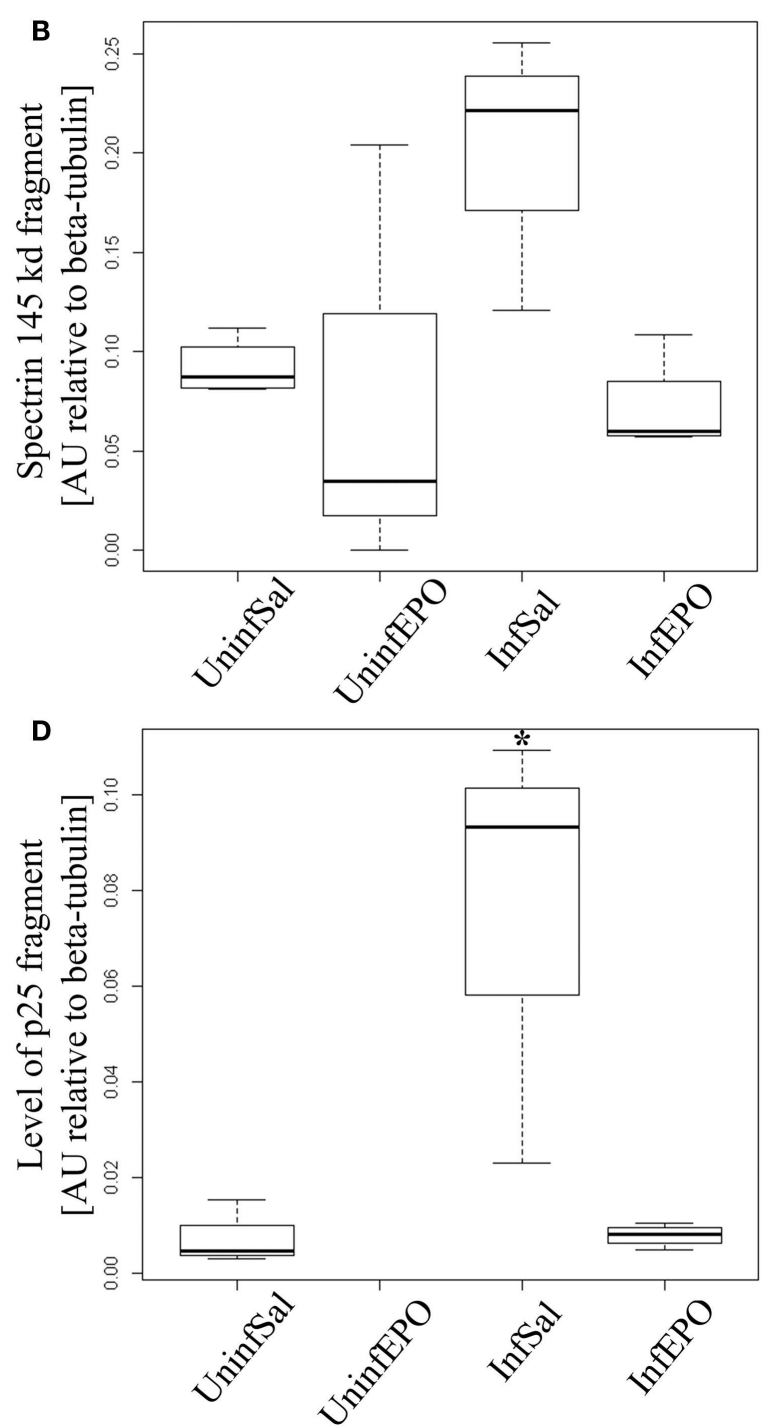

specific for caspase-3 activity was markedly increased in InfSal mice ( $p<0.01$ ). (D) p35 is cleaved by calpain activity into a smaller fragment, p25. This fragment was not detectable in UninfEPO mice, but was significantly increased in InfSal mice $(p<0.05)$. Box plots show median values and interquartile ranges. Whiskers show Tukey hinges; open circles are outliers. Asterisks denote significant deviations from uninfected, saline-treated mice. be performed using the rodent model. However, most immunological aspects as well as cerebral hypoperfusion and neuropathology have important similarities $(2,5,39)$ making the murine model useful for studying human CM pathogenesis.

Here, we show systemic and cerebral increase in VEGF levels in terminally ill CM mice and show that EPO treatment reduces VEGF levels in the brain. VEGF has several opposing roles: it stimulates the growth of endothelial cells and acts neuroprotectively but also increases the permeability of the BBB $(20,41,42)$. Recently, increased plasma levels of VEGF was shown to be responsible for acute lung injury in another murine model of malaria (28), but VEGF signaling has not been addressed in murine CM. Similar to our previous studies (5), we noticed increased levels of cerebral HIF- $1 \alpha$ in CM mice. This stimulates VEGF expression in the brain (19), in line with our findings in terminally ill CM mice. HIF$1 \alpha$ was not increased in InfEPO mice and consequently VEGF remained normal in this group. Both hypoxia and inflammation induce VEGF expression, and since both are thought to be part of CM pathogenesis, it is difficult to determine the main inducer of cerebral VEGF expression in our model. Since EPO treatment decreases both cerebral hypoxia (5) and neuroinflammation (14, $15,37)$, the study can not discriminate between the two driving forces for VEGF expression, but conclude that decreased HIF$1 \alpha$ and VEGF expression is associated with markedly improved 

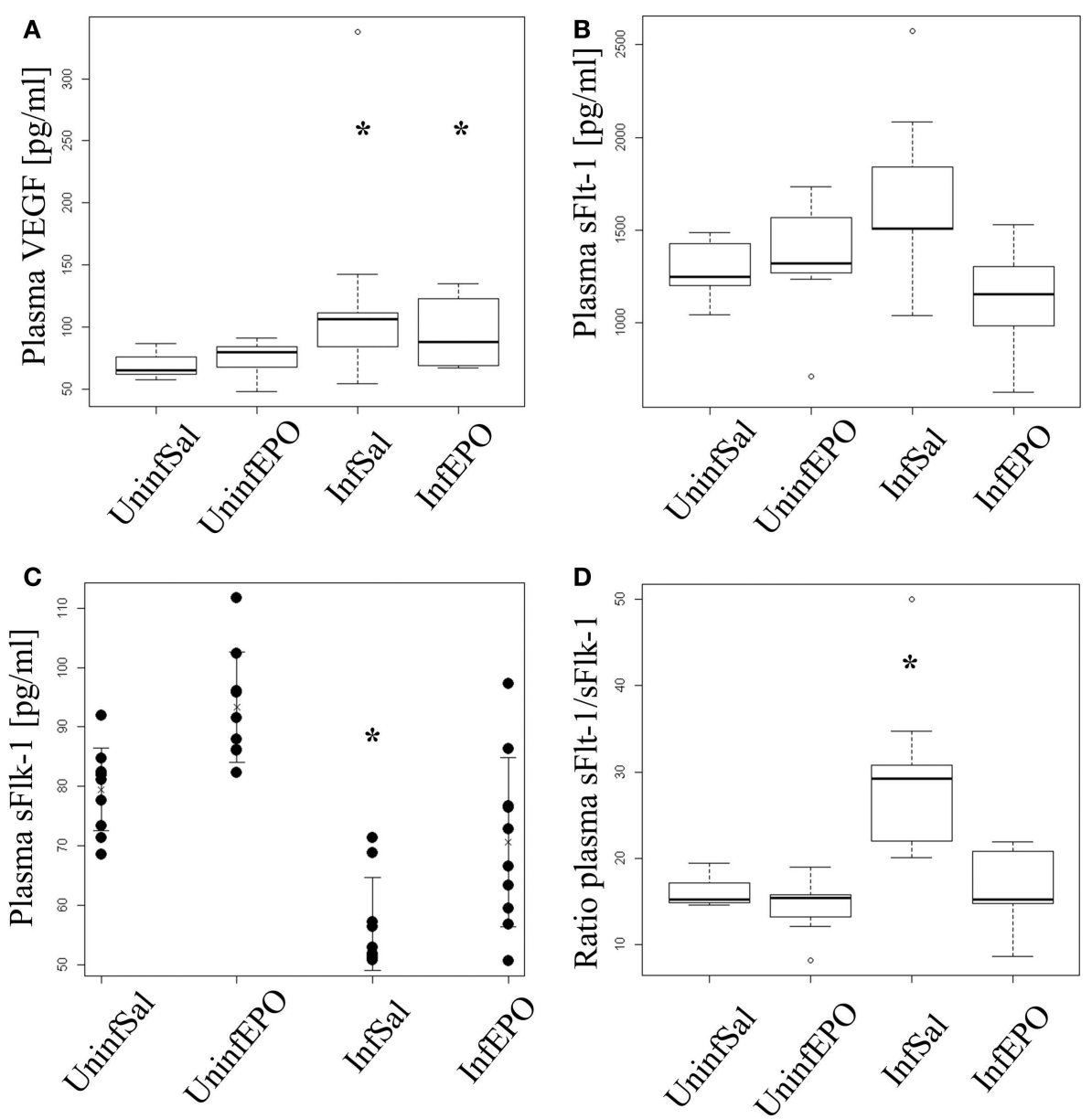

FIGURE 4 | Plasma levels of VEGF, soluble Flt-1 and soluble Flk-1. Plasma was extracted from euthanized mice at day 8 p.i. and analyzed by ELISA. (A) VEGF levels increased significantly due to infection $(p<0.05)$. Both infection groups had significantly increased plasma levels of VEGF ( $p=0.04$ saline-treated, $p=0.03$ EPO-treated). (B) Soluble FIt-11 was largely unaffected by infection and treatment though significant changes were noted $(p=0.02)$. No groups deviated from UninfSal mice $(p>0.14)$. (C) Soluble Flk-1 was significantly affected by both EPO treatment and infection. Soluble Flk-1 levels were significantly decreased due to $\mathrm{CM}$ $(p<0.001)$. On the contrary, EPO treatment led to an increased level of this receptor in both infected $(p=0.03)$ and uninfected mice $(p=0.02)$ compared with the corresponding saline-treated control groups. Yet, infection strongly decreased sFlk-1 levels in EPO-treated mice $(p<0.001)$ compared with UninfEPO mice. (D) When taking the ratio of sFlt-1 to sFlk-1 only InfSal was significantly different from uninfected mice $(p<0.002)$. Box plots (A,B,D) show median values and interquartile ranges. Whiskers show Tukey hinges; open circles are outliers. Strip chart (C) show the mean value as a cross and whiskers represent standard deviation. Each dot represents the plasma level in one mouse. Asterisks denote significant deviations from uninfected, saline-treated mice. clinical outcome of CM. In this study, EPO treatment also reduced parasitemia and may thus introduce bias. However, in previous works $(14,15)$ the effect of EPO was prominent without changed parasitemia.

Interestingly, VEGF can increase the levels of the calciumdependent proteases, the calpains $(43,44)$, that break down the cytoskeleton and lead to vascular reorganization. Increased calpain levels have previously been reported in human and murine CM $(45,46)$. We corroborate these findings as we also found this when blotting for two independent markers of calpain activity: p25 and a $150 \mathrm{kDa}$ fragment of $\alpha$-spectrin. Thus, aberrant VEGF signaling may activate calpains causing endothelial pathology and neuropathology $(38,45)$. We found that EPO therapy reduces cerebral VEGF and markers associated with calpain activity to levels comparable with uninfected mice. However, at present we do not know whether directly blocking VEGF signaling would decrease calpain activity as well. Since plasma VEGF is significantly increased in InfEPO mice this does not seem plausible in this experimental model. Calpain activity can be induced by both hypoxia and inflammatory conditions $(47,48)$ and thus blocking this pathway directly may be more promising as adjunct therapy against CM.

We also corroborate our previous finding of cerebral apoptosis (14). Although apoptosis could not be detected at the mRNA level for caspase-3, histological TUNEL staining detecting DNA fragmentation has clearly demonstrated apoptosis in murine CM (14, $15)$. Here, we detected $\alpha$-spectrin cleavage in brain homogenates to quantify the effect of caspase-3 activity and similar to previous 


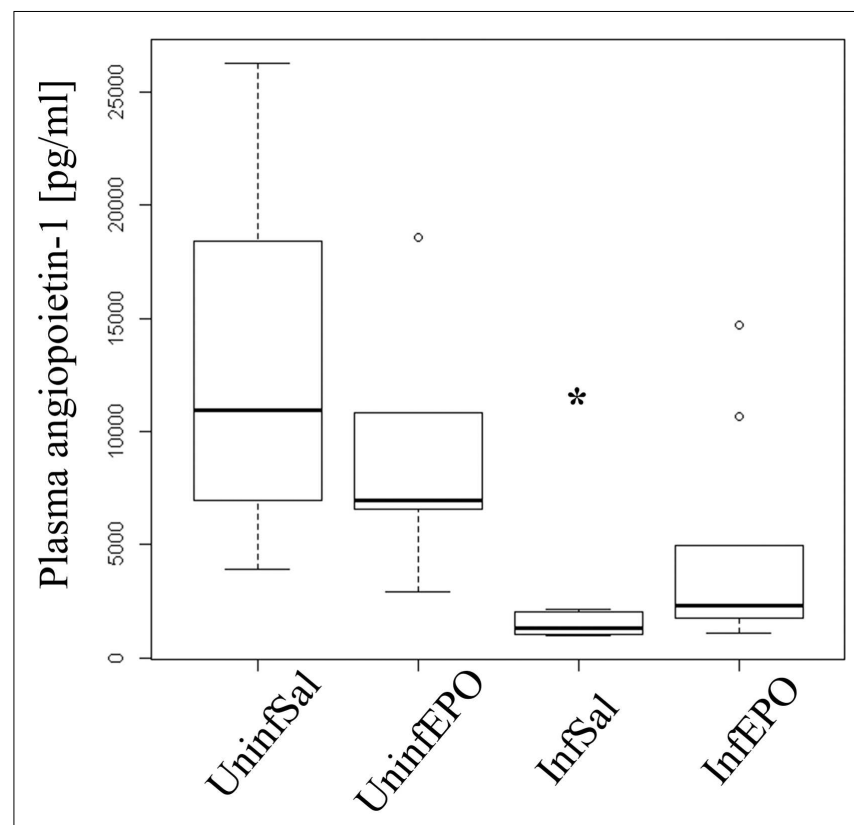

FIGURE 5 | Plasma angiopoietin-1 levels are affected by infection and EPO treatment. In terminal CM, plasma angiopoietin-1 levels were significantly decreased $(p=0.004)$. The, InfEPO group also had lower levels of this cytokine but was statistically similar to uninfected mice $(p=0.06)$. Box plots show median values and interquartile ranges. Whiskers show Tukey hinges; open circles are outliers. Asterisks denote significant deviations from uninfected, saline-treated mice.

findings, EPO treatment reduced cerebral apoptosis to levels similar to uninfected mice.

Cerebral hypoxia leads to the stabilization of HIF- $1 \alpha$ and HIF$2 \alpha$ (49-51). We only detected a significant increase in HIF- $1 \alpha$ and its downstream regulated protein VEGF, whereas cerebral HIF$2 \alpha$ and EPO levels remained unchanged. Others have shown an increase of cerebral EPO at the mRNA level (15), suggesting HIF$2 \alpha$ stabilization. However, the use of different mouse strains may contribute to this discrepancy.

Finding reliable plasma markers that can be associated with clinical severity and outcome is of interest for the management of malaria $(24,27,52)$. We studied VEGF and the two receptors responsible for VEGF signaling: Flt-1 and Flk-1 (53) as well as angiopoietin-1. Flk-1 is the main receptor for VEGF-induced signaling while Flt-1 primarily acts as a decoy receptor to quench excessive VEGF; mainly in a soluble, truncated form (sFlt-1) (54). Plasma VEGF was significantly increased in both the InfSal and InfEPO groups and thus not associated with outcome and neuropathology. sFlt-1 remained unchanged in all groups. The drop in sFlk-1 in infected mice was unexpected but may likely promote pro-angiogenic signaling due to increased VEGF bioavailability and in turn improve tissue oxygenation. The sFlt-1/sFlk-1 ratio however, was only significantly changed in mice with clinical CM. These changes in VEGF and soluble receptor levels could contribute to BBB impairment due to VEGF bioavailability $(28,55)$. Hence, EPO seemed to act differently on the cerebral than the systemic regulation of VEGF since plasma VEGF was increased in EPO-treated malaria mice. Intra-cerebral infusions of VEGF in mice has shown that low doses induce neuroinflammation, recruitment of monocytes, and increased BBB permeability with no noticeable effect on the endothelial proliferation (56). Thus, intra-cerebral signaling may promote local neuropathology not associated with circulating levels of VEGF.

The $\mathrm{BBB}$ has received considerable interest in relation to $\mathrm{CM}$ pathogenesis. It forms a selectively permeable barrier between the central nervous system and the periphery. It also serves as anchoring point for platelets, leukocytes and infected erythrocytes perturbing the microcirculation in $\operatorname{CM}(2,6,57-59)$. Another arm of angiogenesis is the angiopoietin-Tie-2 pathway. Angiopoietin1 and -2 signal via the Tie- 2 receptor and are reliable markers of endothelial activation $(24,27)$. They are also predictable biomarkers of malaria severity $(60,61)$. Angiopoietin-1 upkeeps endothelial stability, while angiopoietin-2 stimulates endothelial remodeling. We measured a significant drop in angiopoietin-1 in murine $\mathrm{CM}$, which suggests considerable endothelial activation and instability. Interestingly, InfEPO mice also had very low levels of angiopoietin-1 suggesting that endothelial function may be perturbed in these mice as well. A recent study of murine CM showed that EPO therapy decreased BBB permeability and endothelial inflammation (37), suggesting that the barrier function is still preserved in EPO-treated mice. However, in that study (37), mice were treated with EPO at day 2-4 p.i., hampering direct comparison with our study. It could be hypothesized that the endothelium is affected and activated in InfEPO mice, yet maintaining its integrity and keeping the BBB selectively permeable despite the increased VEGF and decreased angiopoietin-1 levels in plasma. CM has been termed by some as a vasculopathy (62), and studying the effects of EPO in mice without cerebral, endothelial EPO receptors (63) would be highly relevant for assessing the contributions from endothelium to $\mathrm{CM}$ pathogenesis.

In conclusion, these data show highly upregulated VEGF signaling in terminal, murine CM. Increased cerebral VEGF may directly contribute to neuropathology by promoting monocyte extravasation (56), BBB disruption, and calpain activity. Calpain activity is also increased in human CM (45) and inhibition of this pathway should be studied further. EPO reduces both hypoxia (64) and inflammation in murine $\mathrm{CM}(14,15,37)$, which likely prevents the upregulation of VEGF signaling pathway in the brain. Plasma VEGF was increased significantly in InfEPO mice and angiopoietin-1 levels were also decreased though insignificantly. These findings point toward EPO having a prominent role in neuroprotection in murine $\mathrm{CM}$ while a more modest role on the systemic levels of potential biomarkers of disease severity.

\section{AUTHOR CONTRIBUTIONS}

Casper Hempel designed the experiment, carried out animal studies, performed the western blots, drafted the manuscript. Nils Hoyer performed ELISA experiments of plasma samples and analyses. Anna Kildemoes performed ELISA experiments of plasma and brain samples. Charlotte Bille Jendresen carried out animal studies and prepared brain homogenates. Jørgen Anders Lindholm Kurtzhals contributed to the design of experiments. All authors critically revised the manuscript and approved the final version for publication. 


\section{ACKNOWLEDGMENTS}

Help from Marianne Kristensen (University of Copenhagen) with handling and perfusion of mice is much appreciated. The use of the chemiDoc station at Centre for Inflammation and Metabolism (CIM, University of Copenhagen) is highly appreciated.

\section{REFERENCES}

1. Hay SI, Okiro EA, Gething PW, Patil AP, Tatem AJ, Guerra CA, et al. Estimating the global clinical burden of Plasmodium falciparum malaria in 2007. PLoS Med (2010) 7:e1000290. doi:10.1371/journal.pmed.1000290

2. van der Heyde HC, Nolan J, Combes V, Gramaglia I, Grau GE. A unified hypothesis for the genesis of cerebral malaria: sequestration, inflammation and hemostasis leading to microcirculatory dysfunction. Trends Parasitol (2006) 22:503-8. doi:10.1016/j.pt.2006.09.002

3. Warrell DA, White NJ, Veall N, Looareesuwan S, Chanthavanich P, Phillips RE, et al. Cerebral anaerobic glycolysis and reduced cerebral oxygen transport in human cerebral malaria. Lancet (1988) 2:534-8. doi:10.1016/S0140-6736(88) 92658-X

4. Penet MF, Viola A, Confort-Gouny S, Le FY, Duhamel G, Kober F, et al. Imaging experimental cerebral malaria in vivo: significant role of ischemic brain edema. J Neurosci (2005) 25:7352-8. doi:10.1523/JNEUROSCI.1002-05.2005

5. Hempel C, Combes V, Hunt NH, Lindholm Kurtzhals JA, Raymond Grau GE. CNS hypoxia is more pronounced in murine cerebral than noncerebral malaria and reversed by erythropoietin. Am J Pathol (2011) 179:1939-50. doi:10.1016/j.ajpath.2011.06.027

6. Beare NA, Harding SP, Taylor TE, Lewallen S, Molyneux ME. Perfusion abnormalities in children with cerebral malaria and malarial retinopathy. J Infect Dis (2009) 199:263-71. doi:10.1086/595735

7. Maiese K, Chong ZZ, Li F, Shang YC. Erythropoietin: elucidating new cellular targets that broaden therapeutic strategies. Prog Neurobiol (2008) 85:194-213. doi:10.1016/j.pneurobio.2008.02.002

8. Ratcliffe PJ. HIF-1 and HIF-2: working alone or together in hypoxia? J Clin Invest (2007) 117:862-5. doi:10.1172/JCI31750

9. Semenza G. Signal transduction to hypoxia-inducible factor 1. Biochem Pharmacol (2002) 64:993-8. doi:10.1016/S0006-2952(02)01168-1

10. Skuli N, Majmundar AJ, Krock BL, Mesquita RC, Mathew LK, Quinn ZL, et al. Endothelial HIF-2alpha regulates murine pathological angiogenesis and revascularization processes. J Clin Invest (2012) 122:1427-43. doi:10.1172/ JCI57322

11. Warnecke C, Zaborowska Z, Kurreck J, Erdmann VA, Frei U, Wiesener M, et al. Differentiating the functional role of hypoxia-inducible factor (HIF)-1alpha and HIF-2alpha (EPAS-1) by the use of RNA interference: erythropoietin is a HIF-2alpha target gene in Hep3B and Kelly cells. FASEB J (2004) 18:1462-4. doi:10.1096/fj.04-1640fje

12. Ghezzi P, Brines M. Erythropoietin as an antiapoptotic, tissue-protective cytokine. Cell Death Differ (2004) 11(Suppl 1):S37-44. doi:10.1038/sj.cdd. 4401450

13. Brines ML, Ghezzi P, Keenan S, Agnello D, de Lanerolle NC, Cerami C, et al. Erythropoietin crosses the blood-brain barrier to protect against experimental brain injury. Proc Natl Acad Sci U S A (2000) 97:10526-31. doi:10.1073/pnas. 97.19.10526

14. Wiese L, Hempel C, Penkowa M, Kirkby N, Kurtzhals JA. Recombinant human erythropoietin increases survival and reduces neuronal apoptosis in a murine model of cerebral malaria. Malar J (2008) 7:3. doi:10.1186/1475-2875-7-3

15. Kaiser K, Texier A, Ferrandiz J, Buguet A, Meiller A, Latour C, et al. Recombinant human erythropoietin prevents the death of mice during cerebral malaria. J Infect Dis (2006) 193:987-95. doi:10.1086/500844

16. Bienvenu AL, Ferrandiz J, Kaiser K, Latour C, Picot S. Artesunate-erythropoietin combination for murine cerebral malaria treatment. Acta Trop (2008) 106(2):104-8. doi:10.1016/j.actatropica.2008.02.001

17. Picot S, Bienvenu AL, Konate S, Sissoko S, Barri A, Diarra E, et al. Safety of epoietin beta-quinine drug combination in children with cerebral malaria in Mali. Malar J (2009) 8:169. doi:10.1186/1475-2875-8-169

18. Fong GH. Regulation of angiogenesis by oxygen sensing mechanisms. J Mol Med (2009) 87:549-60. doi:10.1007/s00109-009-0458-z

19. Zhong XS, Zheng JZ, Reed E, Jiang BH. SU5416 inhibited VEGF and HIF-1alpha expression through the PI3K/AKT/p70S6K1 signaling pathway. Biochem Biophys Res Commun (2004) 324:471-80. doi:10.1016/j.bbrc.2004.09.082
20. Brekken RA, Huang X, King SW, Thorpe PE. Vascular endothelial growth factor as a marker of tumor endothelium. Cancer Res (1998) 58:1952-9.

21. Lee HS, Han J, Bai HJ, Kim KW. Brain angiogenesis in developmental and pathological processes: regulation, molecular and cellular communication at the neurovascular interface. FEBS J (2009) 276:4622-35. doi:10.1111/j.1742-4658. 2009.07174.x

22. Deininger MH, Winkler S, Kremsner PG, Meyermann R, Schluesener HJ. Angiogenic proteins in brains of patients who died with cerebral malaria. J Neuroimmunol (2003) 142:101-11. doi:10.1016/S0165-5728(03)00250-9

23. Casals-Pascual C, Idro R, Gicheru N, Gwer S, Kitsao B, Gitau E, et al. High levels of erythropoietin are associated with protection against neurological sequelae in African children with cerebral malaria. Proc Natl Acad Sci U S A (2008) 105:2634-9. doi:10.1073/pnas.0709715105

24. Jain V, Armah HB, Tongren JE, Ned RM, Wilson NO, Crawford S, et al. Plasma IP-10, apoptotic and angiogenic factors associated with fatal cerebral malaria in India. Malar J (2008) 7:83. doi:10.1186/1475-2875-7-83

25. Furuta T, Kimura M, Watanabe N. Elevated levels of vascular endothelial growth factor (VEGF) and soluble vascular endothelial growth factor receptor (VEGFR)-2 in human malaria. Am J Trop Med Hyg (2010) 82:136-9. doi:10.4269/ajtmh.2010.09-0203

26. Medana IM, Day NP, Roberts R, Sachanonta N, Turley H, Pongponratn E, et al. Induction of the vascular endothelial growth factor pathway in the brain of adults with fatal falciparum malaria is a non-specific response to severe disease. Histopathology (2010) 57:282-94. doi:10.1111/j.1365-2559.2010.03619.x

27. Conroy AL, Phiri H, Hawkes M, Glover S, Mallewa M, Seydel KB, et al. Endothelium-based biomarkers are associated with cerebral malaria in Malawian children: a retrospective case-control study. PLoS One (2010) 5:e15291. doi:10.1371/journal.pone.0015291

28. Epiphanio S, Campos MG, Pamplona A, Carapau D, Pena AC, Ataide R, et al. VEGF promotes malaria-associated acute lung injury in mice. PLoS Pathog (2010) 6:e1000916. doi:10.1371/journal.ppat.1000916

29. Hein-Kristensen L, Wiese L, Kurtzhals JA, Staalsoe T. In-depth validation of acridine orange staining for flow cytometric parasite and reticulocyte enumeration in an experimental model using Plasmodium berghei. Exp Parasitol (2009) 123:152-7. doi:10.1016/j.exppara.2009.06.010

30. DellaValle B, Staalsoe T, Kurtzhals JA, Hempel C. Investigation of hydrogen sulfide gas as a treatment against $P$. falciparum, murine cerebral malaria, and the importance of thiolation state in the development of cerebral malaria. PLoS ONE (2013) 8:e59271. doi:10.1371/journal.pone.0059271

31. Curfs JH, Schetters TP, Hermsen CC, Jerusalem CR, van Zon AA, Eling WM. Immunological aspects of cerebral lesions in murine malaria. Clin Exp Immunol (1989) 75:136-40.

32. Development Core R. Team R: A Language and Environment for Statistical Computing. Vienna: R Foundation for Statistical Computing (2008).

33. Core A, Hempel C, Kurtzhals JA, Penkowa M. Plasmodium berghei ANKA: erythropoietin activates neural stem cells in an experimental cerebral malaria model. Exp Parasitol (2011) 127:500-5. doi:10.1016/j.exppara.2010.09.010

34. Newcomb JK, Pike BR, Zhao X, Hayes RL. Concurrent assessment of calpain and caspase-3 activity by means of western blots of protease-specific spectrin breakdown products. Methods Mol Biol (2000) 144:219-23. doi:10.1385/1-59259050-0:219

35. London NR, Whitehead KJ, Li DY. Endogenous endothelial cell signaling systems maintain vascular stability. Angiogenesis (2009) 12:149-58. doi:10.1007/ s10456-009-9130-z

36. Lovegrove FE, Tangpukdee N, Opoka RO, Lafferty EI, Rajwans N, Hawkes M, et al. Serum angiopoietin-1 and -2 levels discriminate cerebral malaria from uncomplicated malaria and predict clinical outcome in African children. PLoS One (2009) 4:e4912. doi:10.1371/journal.pone.0004912

37. Wei X, Li Y, Sun X, Zhu X, Feng Y, Liu J, et al. Erythropoietin protects against murine cerebral malaria through actions on host cellular immunity. Infect Immun (2013) 82(1):165-73. doi:10.1128/IAI.00929-13

38. Hempel C, Hyttel P, Staalso T, Nyengaard JR, Kurtzhals JA. Erythropoietin treatment alleviates ultrastructural myelin changes induced by murine cerebral malaria. Malar J (2012) 11:216. doi:10.1186/1475-2875-11-216

39. Hunt NH, Grau GE, Engwerda C, Barnum SR, van der Heyde H, Hansen DS, et al. Murine cerebral malaria: the whole story. Trends Parasitol (2010) 26(6):272-4. doi:10.1016/j.pt.2010.03.006

40. White NJ, Turner GD, Medana IM, Dondorp AM, Day NP. The murine cerebral malaria phenomenon. Trends Parasitol (2009). doi:10.1016/j.pt.2009.10.007 
41. Kaya D, Gursoy-Ozdemir Y, Yemisci M, Tuncer N, Aktan S, Dalkara T. VEGF protects brain against focal ischemia without increasing blood - brain permeability when administered intracerebroventricularly. J Cereb Blood Flow Metab (2005) 25:1111-8. doi:10.1038/sj.jcbfm.9600109

42. Argaw AT, Asp L, Zhang J, Navrazhina K, Pham T, Mariani JN, et al. Astrocytederived VEGF-A drives blood-brain barrier disruption in CNS inflammatory disease. J Clin Invest (2012) 122(7):2454-68. doi:10.1172/JCI60842

43. Hoang MV, Nagy JA, Fox JE, Senger DR. Moderation of calpain activity promotes neovascular integration and lumen formation during VEGF-induced pathological angiogenesis. PLoS ONE (2010) 5:e13612. doi:10.1371/journal. pone. 0013612

44. Su Y, Cui Z, Li Z, Block ER. Calpain-2 regulation of VEGF-mediated angiogenesis. FASEB J (2006) 20:1443-51. doi:10.1096/fj.05-5354com

45. Medana IM, Day NP, Hien TT, Mai NT, Bethell D, Phu NH, et al. Cerebral calpain in fatal falciparum malaria. Neuropathol Appl Neurobiol (2007) 33:179-92. doi:10.1111/j.1365-2990.2006.00777.x

46. Shukla M, Rajgopal Y, Babu PP. Activation of calpains, calpastatin and spectrin cleavage in the brain during the pathology of fatal murine cerebral malaria. Neurochem Int (2006) 48:108-13. doi:10.1016/j.neuint.2005.09.001

47. Das A, Guyton MK, Butler JT, Ray SK, Banik NL. Activation of calpain and caspase pathways in demyelination and neurodegeneration in animal model of multiple sclerosis. CNS Neurol Disord Drug Targets (2008) 7:313-20. doi: $10.2174 / 187152708784936699$

48. Hoang MV, Smith LE, Senger DR. Calpain inhibitors reduce retinal hypoxia in ischemic retinopathy by improving neovascular architecture and functional perfusion. Biochim Biophys Acta (2010) 1812(4):549-57. doi:10.1016/j.bbadis. 2010.08.008

49. Chavez JC, Baranova O, Lin J, Pichiule P. The transcriptional activator hypoxia inducible factor 2 (HIF-2/EPAS-1) regulates the oxygen-dependent expression of erythropoietin in cortical astrocytes. J Neurosci (2006) 26:9471-81. doi:10.1523/JNEUROSCI.2838-06.2006

50. Yeo EJ, Cho YS, Kim MS, Park JW. Contribution of HIF-1alpha or HIF-2alpha to erythropoietin expression: in vivo evidence based on chromatin immunoprecipitation. Ann Hematol (2008) 87:11-7. doi:10.1007/s00277-007-0359-6

51. Yeh SH, Ou LC, Gean PW, Hung JJ, Chang WC. Selective inhibition of earlybut not late-expressed HIF-1alpha is neuroprotective in rats after focal ischemic brain damage. Brain Pathol (2010) 21(3):249-62. doi:10.1111/j.1750-3639.2010. 00443.x

52. Armah HB, Wilson NO, Sarfo BY, Powell MD, Bond VC, Anderson W, et al. Cerebrospinal fluid and serum biomarkers of cerebral malaria mortality in Ghanaian children. Malar J (2007) 6:147. doi:10.1186/1475-2875-6-147

53. Kanno S, Oda N, Abe M, Terai Y, Ito M, Shitara K, et al. Roles of two VEGF receptors, Flt- 1 and KDR, in the signal transduction of VEGF effects in human vascular endothelial cells. Oncogene (2000) 19:2138-46. doi:10.1038/sj.onc.1203533

54. Robinson CJ, Stringer SE. The splice variants of vascular endothelial growth factor (VEGF) and their receptors. J Cell Sci (2001) 114:853-65.

55. Schoch HJ, Fischer S, Marti HH. Hypoxia-induced vascular endothelial growth factor expression causes vascular leakage in the brain. Brain (2002) 125:2549-57. doi:10.1093/brain/awf257
56. Croll SD, Ransohoff RM, Cai N, Zhang Q, Martin FJ, Wei T, et al. VEGFmediated inflammation precedes angiogenesis in adult brain. Exp Neurol (2004) 187:388-402. doi:10.1016/j.expneurol.2004.02.010

57. Grau GE, Tacchini-Cottier F, Vesin C, Milon G, Lou JN, Piguet PF, et al. TNFinduced microvascular pathology: active role for platelets and importance of the LFA-1/ICAM-1 interaction. Eur Cytokine Netw (1993) 4:415-9.

58. Grau GE, Mackenzie CD, Carr RA, Redard M, Pizzolato G, Allasia C, et al. Platelet accumulation in brain microvessels in fatal pediatric cerebral malaria. $J$ Infect Dis (2003) 187:461-6. doi:10.1086/367960

59. Ma N, Hunt NH, Madigan MC, Chan-Ling T. Correlation between enhanced vascular permeability, up-regulation of cellular adhesion molecules and monocyte adhesion to the endothelium in the retina during the development of fatal murine cerebral malaria. Am J Pathol (1996) 149:1745-62.

60. Conroy AL, Lafferty EI, Lovegrove FE, Krudsood S, Tangpukdee N, Liles WC, et al. Whole blood angiopoietin-1 and -2 levels discriminate cerebral and severe (non-cerebral) malaria from uncomplicated malaria. Malar J (2009) 8:295. doi:10.1186/1475-2875-8-295

61. Jain V, Lucchi NW, Wilson NO, Blackstock AJ, Nagpal AC, Joel PK, et al. Plasma levels of angiopoietin-1 and -2 predict cerebral malaria outcome in Central India. Malar J (2011) 10:383. doi:10.1186/1475-2875-10-383

62. Desruisseaux MS, Machado FS, Weiss LM, Tanowitz HB, Golightly LM. Cerebral malaria: a vasculopathy. Am J Pathol (2010) 176:1075-8. doi:10.2353/ajpath. 2010.091090

63. Chen ZY, Asavaritikrai P, Prchal JT, Noguchi CT. Endogenous erythropoietin signaling is required for normal neural progenitor cell proliferation. J Biol Chem (2007) 282:25875-83. doi:10.1074/jbc.M701988200

64. Hempel C, Combes V, Hunt NH, Kurtzhals JA, Grau GE. CNS hypoxia is more pronounced in murine cerebral than noncerebral malaria and is reversed by erythropoietin. Am J Pathol (2011) 179:1939-50. doi:10.1016/j.ajpath.2011. 06.027

Conflict of Interest Statement: The authors declare that the research was conducted in the absence of any commercial or financial relationships that could be construed as a potential conflict of interest.

Received: 08 March 2014; accepted: 03 June 2014; published online: 19 June 2014. Citation: Hempel C, Hoyer N, Kildemoes A, Jendresen CB and Kurtzhals JAL (2014) Systemic and cerebral vascular endothelial growth factor levels increase in murine cerebral malaria along with increased calpain and caspase activity and can be reduced by erythropoietin treatment. Front. Immunol. 5:291. doi: 10.3389/fimmu.2014.00291

This article was submitted to Inflammation, a section of the journal Frontiers in Immunology.

Copyright (C) 2014 Hempel, Hoyer, Kildemoes, Jendresen and Kurtzhals. This is an open-access article distributed under the terms of the Creative Commons Attribution License (CC BY). The use, distribution or reproduction in other forums is permitted, provided the original author(s) or licensor are credited and that the original publication in this journal is cited, in accordance with accepted academic practice. No use, distribution or reproduction is permitted which does not comply with these terms. 